\title{
Factors Associated with Burnout among Healthcare Workers during an Outbreak of MERS
}

\author{
Yae Eun Seo', Hyun Chung Kim¹, So Young Yoo', Kang Uk Lee², Hae Woo Lee ${ }^{3}$, and So Hee Lee ${ }^{1 凶}$ \\ ${ }^{1}$ Department of Psychiatry, National Medical Center, Seoul, Republic of Korea \\ ${ }^{2}$ Department of Psychiatry, Kangwon National University Hospital, Chuncheon, Republic of Korea \\ ${ }^{3}$ Department of Psychiatry, Seoul Medical Center, Seoul, Republic of Korea
}

\begin{abstract}
Objective Although healthcare workers (HCWs) experienced significant stress during the 2015 outbreak of Middle East Respiratory Syndrome (MERS), the factors associated with this stress remain unknown. Thus, the present study assessed burnout among HCWs during the MERS outbreak to identify the influential factors involved in this process.
\end{abstract}

Methods This study was a retrospective chart review of the psychological tests and questionnaires completed by 171 hospital employees from two general hospitals that treated MERS patients. The tests included the Oldenburg Burnout Inventory, Positive Resources Test, the questionnaires assessed exposure to the MERS outbreak event and perceptions about MERS.

Results Of the $171 \mathrm{HCWs,} 112$ (65.5\%) experienced disengagement and 136 (79.5\%) suffered from exhaustion. Disengagement was associated with lower levels of purpose and hope, a higher perception of job risk, and exposure to the media. Exhaustion was associated with lower levels of purpose and hope, a higher perception of little control of the infection, a higher perception of job risk, prior experience related to infections, and being female.

Conclusion Our results revealed the risk and protective factors associated with burnout among HCWs during an outbreak of MERS. These findings should be considered when determining interventional strategies aimed at ameliorating burnout among HCWs.

Psychiatry Investig 2020;17(7):674-680

Key Words Burnout, Middle East Respiratory Syndrome, Infectious disease, Healthcare workers.

\section{INTRODUCTION}

Middle East Respiratory Syndrome (MERS) is a respiratory disease that can result in death. It was first reported in September 2012 in Saudi Arabia and then spread throughout the world in 2015. ${ }^{1}$ South Korea had the second highest number of MERS cases in the world $(n=186)$ and 38 people died. ${ }^{2}$ During an outbreak of an infectious disease, healthcare workers (HCWs) are easily exposed to intense psychological responses. Thus, burnout is an important factor to consider during such events because it results in HCWs detaching themselves from work and performing at a suboptimal level., ${ }^{3,4}$ Burnout is a state of physi-

Received: February 10, 2020 Revised: April 2, 2020

Accepted: May 10, 2020

$\triangle$ Correspondence: So Hee Lee, MD, PhD

Department of Psychiatry, National Medical Center, 245 Eulji-ro, Jung-gu, Seoul 04564, Republic of Korea

Tel: +82-2-2260-7311, Fax: +82-2-2268-5028, E-mail: sohee.lee@nmc.or.kr

(c) This is an Open Access article distributed under the terms of the Creative Commons Attribution Non-Commercial License (https://creativecommons.org/licenses/bync/4.0) which permits unrestricted non-commercial use, distribution, and reproduction in any medium, provided the original work is properly cited. cal and emotional depletion that results from persistent exposure to stressful working conditions. ${ }^{5}$ This state consists of exhaustion, which is associated with feelings of emptiness, being drained, and a desire to rest, as well as the experience of disengagement, which results in cynical behavior and distancing oneself from work. ${ }^{6}$ Cimiotti et al. ${ }^{7}$ emphasized that reducing burnout is an important factor when fighting infectious disease in acute care facilities.

Considerable research has assessed burnout in HCWs. For example, Edwards et al. ${ }^{8}$ suggested that burnout in HCWs is affected by organizational factors such as increased workload, time pressures, safety issues, role ambiguity, lack of supervision, and reduced resources. In addition, individual factors such as physical illness, personality, coping strategies, and job attitude also play an influential role.-11 Maunder et al. ${ }^{12}$ assessed burnout in HCWs during the 2003 outbreak of Severe Acute Respiratory Syndrome (SARS) and found that perceived adequacy of training, support, and an adaptive coping style are protective against burnout.

However, few studies have investigated burnout during or 
after a MERS outbreak. Kim and $\mathrm{Choi}^{13}$ examined burnout after MERS in terms of job stress caused by MERS, fear of MERS infection, hospital resources for the treatment of MERS, and support from family and friends. Although they found that job stress, poor hospital resources, and poor support from family and friends explained $47.3 \%$ of burnout, they did not examine whether personal strength or coping could prevent burnout or how experiences at the time of the incident and perceptions about epidemic disease impact it. Thus, we invested the proportion of HCWs that suffered from burnout (i.e., engagement and exhaustion) during the 2015 outbreak of MERS and the protective and/or risk factors associated with it (i.e., engagement and exhaustion).

\section{METHODS}

\section{Setting and sample}

The present study was conducted between June 2015 and June 2016 during the MERS outbreak. A retrospective chart review of psychological tests completed by 171 hospital employees from two general hospitals that treated MERS patients was conducted; the sample consisted of 32 doctors, 77 nurses, and 61 others (i.e., pharmacists, technician, officers, and so forth). Approval was obtained from the Institutional Review Board of National Medical Center in Korea (no. H-1507-056-004).

\section{Measurements}

\section{Burnout}

Burnout was measured with the Oldenburg Burnout Inventory (OLBI), which was validated in Korean by Na. ${ }^{14,15}$ This scale includes 16 items: 8 measure exhaustion (e.g., "There are days when I feel tired before I arrive at work") and 8 measure disengagement (e.g., "It happens more and more often that I talk about my work in a negative way"). Each of the subscales includes four positively worded items and four negatively worded items and each item is scored on a scale ranging from 1 (strongly agree) to 4 (strongly disagree). As described in a previous study, the following cutoff scores were defined as high: $\geq 16.8$ for disengagement and $\geq 18$ for exhaustion. ${ }^{16}$ In the present study, the Cronbach's alpha values were 0.70 for disengagement and 0.82 for exhaustion.

\section{Positive resources}

Positive resources were measured with the Positive Resources Test, which was developed and validated in Korean by Huh et al. ${ }^{17}$ This measure includes 23 items scored on a five-point scale ranging from 1 (strongly disagree) to 5 (strongly agree). Scores are generated for five subscales: optimism, purpose and hope, self-regulation, social support, and caring and serving.
Their Cronbach's alpha values were $0.79,0.78,0.55,0.70$, and 0.81 , respectively.

\section{Exposure to MERS}

Participants also answered the following questions about their exposure to MERS: "Have you been within 2 meters of a MERS patient while not wearing personal protective equipment (PPE)?", "Have you treated MERS patients in person while wearing PPE?," "Have you experiences MERS-like symptoms after contact with MERS patients?", "Have you ever been quarantined?," "Have your hospital or employees been exposed to media reports about the MERS outbreak, such as TV, internet, radio and so on?" All questions were answered with either "yes" or "no."

\section{Perceptions about MERS}

Perceptions about MERS were assessed with a 10 -item measure similar to the one described by Chong et al. ${ }^{18}$ Questions addressed the following: perceived job risk, acceptance, fear of falling ill with MERS, lack of control over infection, chance of survival if infected, fear of infecting others with MERS, concern about infecting family and friends, and other's avoidance of their family because of their work. Each item was answered on a 5 -point scale ranging from 1 (strongly disagree) to 5 (strongly agree). Because items were heterogeneous, we treated each item as a separate variable (Table 1 ).

\section{Data analyses}

All data were analyzed using SPSS for Windows version 22.0 (IBM Corp., Armonk, NY, USA). The means and standard deviations (SD) were calculated for burnout, positive resources, and MERS-related recognition. Categorical data were summarized using frequencies and percentages of occurrence (sex, job title, and so forth). The psychological effects of the MERS outbreak on employees were assessed based on scores on items measuring burnout and factors that might explain the variance in burnout were identified using between-group differences and correlation analyses. Between-group differences in para-

Table 1. Major items of perception about MERS

\begin{tabular}{l} 
Items \\
\hline My job puts me at great risk \\
I accept the risk of caring for MERS patients \\
I am afraid of falling ill with MERS \\
I have little control over whether I get infected or not \\
I have little chance of survival if I were to get MERS \\
I am afraid I will pass MERS to others \\
My family and friends are worried they might get infected \\
through me \\
People avoid my family because of my work \\
MERS: Middle East Respiratory Syndrome
\end{tabular}


metric variables were determined using Student's t-tests and analysis of variance (ANOVA) and differences in non-parametric variables were determined using Mann-Whitney $U$ tests. Correlation analyses were performed on continuous variables. Stepwise regression analyses were performed to performed to derive predictive model for burnout. All factors identified as significant by the difference tests and correlation analyses were included as predictor variables and burnout (exhaustion, disengagement) was treated as the criterion variable. Statistical significance was set at $\alpha=0.05$ (two-tailed).

\section{RESULTS}

\section{General characteristics}

Table 2 presents the characteristics of the total sample. Of the 171 participants, the mean age was 34.2 years ( $\mathrm{SD}=9.8$ ), $66.1 \%$ were female, $45.3 \%$ were nurses, $18.8 \%$ were doctors, $17.65 \%$ were pharmacists or other healthcare workers, $18.24 \%$ were technicians or office workers, and $88.7 \%$ had received MERS education. In addition, 3.5\% were exposed to one or more MERS patients within $2 \mathrm{~m}$ without personal protective equipment (PPE), 44\% had cared for MERS patients in person with PPE, 7.3\% experienced MERS-like symptoms, 3\% were quarantined, and $78.6 \%$ responded that their hospital or employees were exposed to MERS-related media.

\section{Prevalence of burnout}

The mean score for disengagement was 17.6 and the mean score for exhaustion was 20.7 (Table 3). More than $65.8 \%$ of participants experienced disengagement and more than $79.5 \%$ experienced exhaustion.

\section{Factors influencing burnout}

To identify the factors that influenced burnout, betweengroup analyses of demographic variables, medical history, traumatic experiences, work-related characteristics, and exposure to MERS were conducted (Table 4). The level of disengagement significantly differed according to sex, work experience, providing care while using PPE, and exposure to media. The level of exhaustion significantly differed according to sex, prior traumatic events, prior experience related to infection, job type, providing care while using PPE, and exposure to media.

Correlation analyses were performed to assess positive resources and perceptions about MERS (Table 5). The level of disengagement was significantly correlated with optimism, purpose and hope, self-regulation, caring and serving, perceived job risk, fear of falling ill with MERS, lack of control over infection, little chance of survival if infected, fear of passing MERS to others, worry of family and friends getting infected through oneself, and avoiding one's family because of one's work. The
Table 2. General characteristics of the participants $(N=171)$

\begin{tabular}{|c|c|c|}
\hline & $\mathrm{N}(\%)$ & $\mathrm{M}(\mathrm{SD})$ \\
\hline \multicolumn{3}{|l|}{ Sociodemographic variables } \\
\hline \multicolumn{3}{|l|}{ Gender } \\
\hline Female & $113(66.1)$ & \\
\hline Male & $58(33.9)$ & \\
\hline Age & & $34.2(9.8)$ \\
\hline \multicolumn{3}{|l|}{ Job type } \\
\hline Doctor & $32(18.8)$ & \\
\hline Nurse & $77(45.3)$ & \\
\hline Pharmacist, other health care worker & $30(17.65)$ & \\
\hline Technician, office worker & $31(18.24)$ & \\
\hline \multicolumn{3}{|l|}{ Working experience } \\
\hline$<3$ year & $51(30.0)$ & \\
\hline $3-10$ year & $69(40.6)$ & \\
\hline$>10$ year & $50(29.4)$ & \\
\hline MERS education & $149(88.7)$ & \\
\hline \multicolumn{3}{|l|}{ Exposure to MERS } \\
\hline Exposure without PPE & $6(3.5)$ & \\
\hline Caring with PPE & $74(44.0)$ & \\
\hline MERS like symptoms & $12(7.3)$ & \\
\hline Quarantined & $5(3.0)$ & \\
\hline Exposure to media & $125(78.6)$ & \\
\hline \multicolumn{3}{|l|}{ Traumatic experiences } \\
\hline Prior traumatic events & $36(21.7)$ & \\
\hline Prior infection experience & $53(32.1)$ & \\
\hline
\end{tabular}

PPE: personal protective equipment, MERS: Middle East Respiratory Syndrome

Table 3. Prevalence of the burnout $(\mathrm{N}=171)$

\begin{tabular}{lcc}
\hline \multicolumn{1}{c}{ Burnout } & $\mathrm{M}(\mathrm{SD})$ & Range $(\%)$ \\
\hline Disengagement $(\geq 16.8)$ & $17.6(2.5)$ & $10-31(65.8)$ \\
Exhaustion $(\geq 18)$ & $20.7(3.5)$ & $9-30(79.5)$ \\
\hline
\end{tabular}

level of exhaustion was significantly correlated with optimism, purpose and hope, self-regulation, social support, perceived job risk, acceptance, fear of falling ill with MERS, lack of control over infection, little chance of survival if infected, fear of passing MERS to others, worry of family and friends getting infected through oneself, and avoiding one's family because of one's work.

Stepwise regression analyses were conducted to determine which variables accounted for significant variance in burnout (Table 6); variables that were significant $(\mathrm{p}<0.05)$ in previous analyses were retained. Purpose and hope, perceived job risk, and exposure to media explained 33\% of disengagement and purpose and hope, lack of control over infection, perceived job risk, prior experience related to infection, and sex explained $38 \%$ of exhaustion. 


\section{DISCUSSION}

We found that $65.5 \%$ of HCWs reported disengagement and
79.5\% reported exhaustion during the 2015 MERS outbreak. In addition, disengagement was associated with lower levels of purpose and hope, the perception of higher job risk, and ex-

Table 4. Relationship of gender, marital status, living with family, medical history, traumatic experience, work-related characteristics, exposure to MERS to burnout

\begin{tabular}{|c|c|c|c|c|c|}
\hline & \multirow{2}{*}{$\mathrm{N}$} & \multicolumn{2}{|c|}{ Disengagement } & \multicolumn{2}{|c|}{ Exhaustion } \\
\hline & & $\mathrm{M}(\mathrm{SD})$ & $\mathrm{t}, \mathrm{F} / \mathrm{p}$ & $\mathrm{M}(\mathrm{SD})$ & t, F/p (scheffe) \\
\hline \multicolumn{6}{|c|}{ Sociodemographical variables } \\
\hline \multicolumn{6}{|c|}{ Gender } \\
\hline Female & 113 & $18.0(2.4)$ & $\mathrm{t}=2.68 / \mathrm{p}=0.016$ & $21.4(3.4)$ & $\mathrm{t}=3.72 / \mathrm{p}<0.001$ \\
\hline Male & 58 & $17(2.6)$ & & $19.3(3.4)$ & \\
\hline \multicolumn{6}{|l|}{ Job type } \\
\hline Doctor $^{1}$ & 32 & $18.4(2.5)$ & $\mathrm{F}=1.63 / \mathrm{p}=0.104$ & $20.8(3.3)$ & $\mathrm{F}=6.12 / \mathrm{p}=0.006(2>3)$ \\
\hline Nurse $^{2}$ & 77 & $17.7(2.4)$ & & $21.4(3.3)$ & \\
\hline Others $^{3}$ & 61 & $17.2(2.6)$ & & $19.6(3.5)$ & \\
\hline \multicolumn{6}{|l|}{ Working experience } \\
\hline$<3$ year & 51 & $17.2(2.6)$ & $\mathrm{F}=3.79 / \mathrm{p}=0.043$ & $20.4(3.1)$ & $\mathrm{F}=0.27 / \mathrm{p}=0.599$ \\
\hline 3-10 year & 69 & $18.2(2.5)$ & & $21.0(3.7)$ & \\
\hline$>10$ year & 50 & $17.3(2.3)$ & & $20.5(3.5)$ & \\
\hline \multicolumn{6}{|l|}{ MERS education } \\
\hline Yes & 149 & $17.6(2.5)$ & $\mathrm{t}=3.67 / \mathrm{p}=0.586$ & $20.6(3.4)$ & $\mathrm{t}=0.98 / \mathrm{p}=0.426$ \\
\hline No & 19 & $17.9(2.6)$ & & $21.3(4.2)$ & \\
\hline \multicolumn{6}{|l|}{ Traumatic experience } \\
\hline \multicolumn{6}{|c|}{ Prior traumatic events } \\
\hline Yes & 36 & $18.1(2.4)$ & $\mathrm{t}=-1.66 / \mathrm{p}=0.148$ & $21.8(3.3)$ & $\mathrm{t}=-2.09 / \mathrm{p}=0.023$ \\
\hline No & 130 & $17.5(2.5)$ & & $20.3(3.4)$ & \\
\hline \multicolumn{6}{|c|}{ Prior experience related to infection } \\
\hline Yes & 53 & $18.1(2.1)$ & $\mathrm{t}=-1.77 / \mathrm{p}=0.052$ & $21.6(3.3)$ & $\mathrm{t}=-2.91 / \mathrm{p}=0.007$ \\
\hline No & 112 & $17.3(2.6)$ & & $20.1(3.3)$ & \\
\hline \multicolumn{6}{|l|}{ Exposure to MERS } \\
\hline \multicolumn{6}{|c|}{ Exposure without PPE } \\
\hline Yes & 6 & $18.8(2.7)$ & $\mathrm{t}=-1.00 / \mathrm{p}=0.231$ & $22.8(2.6)$ & $\mathrm{t}=-1.93 / \mathrm{p}=0.071^{*}$ \\
\hline Uncertain or no & 164 & $17.6(2.5)$ & & $20.6(3.5)$ & \\
\hline \multicolumn{6}{|l|}{ Caring with PPE } \\
\hline Yes & 74 & $18.3(2.7)$ & $\mathrm{t}=2.61 / \mathrm{p}=0.006$ & $21.5(3.7)$ & $\mathrm{t}=-3.00 / \mathrm{p}=0.003$ \\
\hline No & 94 & $17.2(2.2)$ & & $20.0(3.2)$ & \\
\hline \multicolumn{6}{|c|}{ MERS like symptoms } \\
\hline Yes & 12 & $18.7(1.9)$ & $\mathrm{t}=2.06 / \mathrm{p}=0.147$ & $22.5(3.1)$ & $\mathrm{t}=2.15 / \mathrm{p}=0.063$ \\
\hline No & 152 & $17.6(2.5)$ & & $20.6(3.5)$ & \\
\hline \multicolumn{6}{|l|}{ Quarantined } \\
\hline Yes & 5 & $19.4(3.0)$ & $\mathrm{U}=269^{*} / \mathrm{p}=0.289$ & $22.2(4.2)$ & $\mathrm{U}=289^{*} / \mathrm{p}=0.210$ \\
\hline No & 160 & $17.6(2.5)$ & & $20.6(3.5)$ & \\
\hline \multicolumn{6}{|l|}{ Exposure to media } \\
\hline Yes & 125 & $18.0(2.4)$ & $\mathrm{t}=3.73 / \mathrm{p}<0.001$ & $21(3.4)$ & $\mathrm{t}=2.37 / \mathrm{p}=0.014$ \\
\hline No & 34 & $16.3(2.4)$ & & $19.4(3.3)$ & \\
\hline
\end{tabular}

*Mann-Whitney U test 
Table 5. Relationship of the age, positive resources and perception about MERS to the burnout

\begin{tabular}{|c|c|c|c|c|}
\hline & \multicolumn{2}{|c|}{ Disengagement } & \multicolumn{2}{|c|}{ Exhaustion } \\
\hline & Pearson $\mathrm{r}$ & $\mathrm{p}$ & Pearson $\mathrm{r}$ & $\mathrm{p}$ \\
\hline Age & -0.131 & 0.089 & -0.199 & 0.009 \\
\hline \multicolumn{5}{|l|}{ POREST } \\
\hline Optimism & -0.418 & $<0.001$ & -0.412 & $<0.001$ \\
\hline Purpose and hope & -0.455 & $<0.001$ & -0.394 & $<0.001$ \\
\hline Self regulation & -0.381 & $<0.001$ & -0.418 & $<0.001$ \\
\hline Social support & -0.098 & 0.204 & -0.165 & 0.031 \\
\hline Caring and serving & -0.252 & 0.001 & -0.137 & 0.074 \\
\hline \multicolumn{5}{|l|}{ Perception about MERS } \\
\hline Perceived job risk & 0.375 & $<0.001$ & 0.413 & $<0.001$ \\
\hline Acceptance & 0.102 & 0.189 & 0.182 & 0.018 \\
\hline Fear of falling ill with MERS & 0.199 & 0.009 & 0.305 & $<0.001$ \\
\hline Lack of control over infection & 0.256 & 0.001 & 0.387 & $<0.001$ \\
\hline Little chance of survival if infected & 0.163 & 0.034 & 0.185 & 0.016 \\
\hline Fear of passing MERS to others & 0.284 & $<0.001$ & 0.410 & $<0.001$ \\
\hline Worrying of family and friends of getting infected through me & 0.282 & $<0.001$ & 0.374 & $<0.001$ \\
\hline Avoiding my family because of my work & 0.158 & 0.041 & 0.255 & 0.001 \\
\hline
\end{tabular}

Table 6. Variables that explain variance in burnout

\begin{tabular}{|c|c|c|c|}
\hline & $\beta$ & $\mathrm{t}$ & $\mathrm{p}$ \\
\hline \multicolumn{4}{|l|}{ Dependent variable: disengagement } \\
\hline Purpose and hope (in POREST) & -0.321 & -5.971 & 0.000 \\
\hline $\begin{array}{l}\text { Perceived job risk } \\
\text { (in Perception of MERS) }\end{array}$ & 0.457 & 3.346 & 0.001 \\
\hline \multirow[t]{2}{*}{ Exposure to media } & 1.240 & 3.070 & 0.003 \\
\hline & \multicolumn{3}{|c|}{ Model $\mathrm{R}^{2}=0.33$, $\mathrm{p}$-value $<0.001$} \\
\hline \multicolumn{4}{|l|}{ Dependent variable: exhaustion } \\
\hline Purpose and hope (in POREST) & -0.353 & -4.910 & 0.000 \\
\hline $\begin{array}{l}\text { Lack of control over infection } \\
\text { (in Perception of MERS) }\end{array}$ & 0.821 & 3.348 & 0.000 \\
\hline $\begin{array}{l}\text { Perceived job risk } \\
\text { (in Perception of MERS) }\end{array}$ & 0.446 & 2.156 & 0.033 \\
\hline Prior infection work experience & 1.120 & 2.343 & 0.020 \\
\hline Sex & 0.999 & 2.091 & 0.038 \\
\hline & \multicolumn{3}{|c|}{ Model $\mathrm{R}^{2}=0.38, \mathrm{p}$-value $<0.001$} \\
\hline
\end{tabular}

posure to media whereas exhaustion was associated with lower levels of purpose and hope, a lower level of perceived control, and the perception of higher job risk. However, receiving MERS education did not have a significant effect.

It is important to note that the majority of participants in the present study experienced burnout during the outbreak. The rate of burnout was similar to that observed in emergency nurses after the outbreak although the present sample included various job types, including doctors, pharmacists, and technicians. ${ }^{13}$
We also found that, among these groups, nurses reported the highest level of burnout and that women had a higher level of burnout than men. This is in contrast to the findings of Maslach and Jackson, ${ }^{19}$ who reported that men are slightly more vulnerable to burnout than women. It is possible that there were more female nurses than females in the other groups and thus future studies should determine whether high levels of burnout are more affected by sex or job. Nonetheless, our findings suggest that nurses should be a priority of interventions aimed at reducing burnout.

Of the personal strength variables, purpose and hope were the most powerful protective factors against both exhaustion and disengagement. This suggests that people who have purpose and hope can bear hardships and cope well with disastrous situations, which is consistent with previous findings. For example, Youssef found that employees with hope report higher levels of job satisfaction, work happiness, and actual performance. ${ }^{20}$ Similarly, Sherwin et al..$^{21}$ examined occupational burnout among nurses in chronic care rehabilitation units and found that a higher level of hope is significantly associated with lower burnout. Therefore, during an outbreak of epidemic disease, setting attainable purposes and committing to those purposes could aid in the prevention of burnout in HCWs.

We also found that perceptions about MERS were an important variable predicting HCW burnout, particularly in terms of perception of job risk and lack of control. The subjective perception of job risk was a risk factor for both exhaustion and disengagement and lack of control over infection was a risk fac- 
tor for exhaustion. Previous studies have emphasized the importance of a sense of control and security in psychological health and Glass and McKnight revealed a modest association between perceived uncontrollability and burnout. ${ }^{22,23}$ It is possible that one's perception of job risk and feelings of lack of control could result in feelings of helplessness, which in turn would result in HCWs detaching themselves from work and feeling exhausted. Preparedness can increase confidence in the ability to do a job as well as psychological well-being. ${ }^{24} \mathrm{How}-$ ever, our results indicate that receiving MERS education was not protective against burnout, which is inconsistent with previous findings showing that perceived adequacy of training is a significant predictive factor. ${ }^{12}$ Taken together, these findings suggest that MERS education programs should be revised to strengthen safety and have tougher anti-infection measures to better protect against burnout in HCWs.

In terms of experiences at the time of infection, we found that exposure to media was one of the most important factors. When exposed to media, individuals may feel like they are under constant surveillance and could be subjected to negative comments by anonymous people, which may lead to the experience of stress and withdrawal from work. For example, when MERS broke out in Korea, it was common to observe a social stigma against patients who recovered from the infection, the families of infected people, and HCWs. In this type of environment, exposure to media might be stressful and leave HCWs feeling alienated. Volpone and Avery ${ }^{25}$ reported that perceived discrimination based on race, sex, age, family obligation, and/ or sexual orientation is related to psychological withdrawal that leads to physical issues such as lateness, absenteeism, and the intent to quit. Our findings suggest that discrimination in society as well as in the workplace could lead to burnout among HCWs. Thus, social campaigns and practical measures aimed at decreasing excessive public fear and rumors toward HCWs may be helpful. On the other hand, we found that experience of MERS-like symptoms, quarantine, and exposure without the use of PPE were not significantly associated with burnout. It is possible that the number of HCWs who experienced these situations was insufficient to produce significant results.

We also found that prior work experience with infections was related to high levels of exhaustion, which indicates that experienced workers were more likely to feel tired. It is possible that prior work experience with treating infected patients could be traumatic for workers. For example, workers with repeated indirect traumatic experiences are more likely to experience burnout, and thus the identification and treatment of individuals with traumatic work experience may be effective for reducing future burnout in $\mathrm{HCWs}{ }^{26}$ It is also possible that experienced workers might be overloaded and have significant responsibilities. A high work load is related to dissatisfaction at work and differences in quality of care, and thus it may be helpful to properly distribute work responsibilities and focus on experienced workers when intervening to prevent burnout in $\mathrm{HCWs}{ }^{27,28}$

The present study had several limitations that should be considered. First, we included HCWs from only two hospitals, which may limit the generalizability of the results. Second, although we targeted individuals who performed certain tasks related to MERS, we did not assess the exact tasks that they did at that time, and thus it was not possible to determine which specific tasks or experiences were more likely to lead to burnout. Regardless, our findings suggest that HCWs in risky work situations were more vulnerable to burnout. Third, perceptions about MERS and exposure to MERS were not measured using validated scales. Although the subjective perception of infections is a very important factor related to psychological problems, an appropriate scale has yet to be developed. Thus, it will be necessary to develop and validate instruments that can measure subjective attitudes and perceptions about infections. Fourth, the numbers of HCWs who experienced MERS-like symptoms, were quarantined, and who were exposed to MERS without PPE were insufficient to produce significant results. Future studies should include a sufficient number of individuals with these experiences.

The present findings are meaningful in several ways. First, we found that a majority of HCWs in hospitals that treated MERS patients during the outbreak experienced burnout. Second, nurses, women, and experienced workers are more vulnerable to burnout. Third, our findings expand on previous findings by showing that personal strength and perceptions about infections are important factors that predict burnout in HCWs, which emphasizes the importance of personal strength factors, such as purpose and hope, in protecting workers against burnout. On the other hand, perception of high job risk and a sense of a lack of control are risk factors of burnout. Finally, our findings suggest practical ways to reduce burnout. For example, exposure to media is an important factor in burnout, which suggests that guidelines for the media coverage of epidemic diseases should be set.

\section{Acknowledgments}

This study was supported by a grant from the Korean Mental Health Technology R\&D Project, Ministry of Health \& Welfare, Republic of Korea (HL19C0007).

\section{Conflicts of Interest}

The authors have no potential conflicts of interest to disclose.

\section{Author Contributions}

Conceptualization: So Hee Lee. Data curation \& Investigation: Hyun Chung Kim, So Young Yoo, Kang Uk Lee, So Hee Lee. Formal analysis: Yae Eun Seo, Hae Woo Lee. Funding acquisition: So Hee Lee. Writing-original draft: Yae Eun Seo. Writing_review \& editing: So Hee Lee. 


\section{ORCID iDs}

Yae Eun Seo

Hyun Chung Kim

So Young Yoo

Kang Uk Lee

Hae Woo Lee

So Hee Lee https://orcid.org/0000-0003-1353-6958

https://orcid.org/0000-0001-6339-3962

https://orcid.org/0000-0001-9964-126X

https://orcid.org/0000-0002-8123-7581

https://orcid.org/0000-0002-9005-3207 https://orcid.org/0000-0002-0552-2014

\section{REFERENCES}

1. Zaki AM, van Boheemen S, Bestebroer TM, Osterhaus AD, Fouchier RA. Isolation of a novel coronavirus from a man with pneumonia in Saudi Arabia. N Engl J Med 2012;367:1814-1820.

2. Choi JY. An outbreak of Middle East respiratory syndrome coronavirus infection in South Korea, 2015. Yonsei Med J 2015;56:1174-1176

3. Maslach C. Job burnout: new directions in research and intervention. Curr Direct Psychol Sci 2003;12:189-192.

4. Williams ES, Manwell LB, Konrad TR, Linzer M. The relationship of organizational culture, stress, satisfaction, and burnout with physicianreported error and suboptimal patient care: results from the MEMO study. Health Care Manage Rev 2007;32:203-212.

5. Cooper CL, Dewe PJ, O’Driscoll MP. Organizational Stress: A Review and Critique of Theory, Research, and Applications. Thousand Oaks: Sage; 2001.

6. Demerouti E, Bakker AB. The Oldenburg Burnout Inventory: A good alternative to measure burnout and engagement. In: Halbesleben RB, Editor. Handbook of Stress and Burnout in Health Care. Hauppauge, New York: Nova Science Publishers Inc, 2008, p.65-78.

7. Cimiotti JP, Aiken LH, Sloane DM, Wu ES. Nurse staffing, burnout, and health care-associated infection. Am J Infect Control 2012;40:486-490.

8. Edwards D, Burnard P, Coyle D, Fothergill A, Hannigan B. Stress and burnout in community mental health nursing: a review of the literature. J Psychiatr Ment Health Nurs 2000;7:7-14.

9. Adriaenssens J, Gucht VD, Maes S. Determinants and prevalence of burnout in emergency nurses: a systematic review of 25 years of research. Int J Nurs Stud 2015;52:649-661.

10. Firth H, Britton P. 'Burnout', absence and turnover amongst British nursing staff. J Occup Psychol 1989;62:55-59.

11. Hunsaker S, Chen HC, Maughan D, Heaston S. Factors that influence the development of compassion fatigue, burnout, and compassion satisfaction in emergency department nurses. J Nurs Scholarsh 2015;47: 186-194.

12. Maunder RG, Lancee WJ, Balderson KE, Bennett JP, Borgundvaag B, Evans S, et al. Long-term psychological and occupational effects of providing hospital healthcare during SARS outbreak. Emerg Infect Dis 2006;12:1924-1932.

13. Kim JS, Choi JS. Factors influencing emergency nurses' burnout dur- ing an outbreak of Middle East Respiratory Syndrome Coronavirus in Korea. Asian Nurs Res (Korean Soc Nurs Sci) 2016;10:295-299.

14. Demerouti E, Bakker AB, Nachreiner F, Schaufeli WB. The job demands-resources model of burnout. J Appl Psychol 2001;86:499-512.

15. Na YJ. The Construct Validity of the Oldenburg Burnout Inventory (OLBI). Suwon: The Graduate School of Ajou University; 2013.

16. Peterson U, Demerouti E, Bergström G, Åsberg M, Nygrenet A. Work characteristics and sickness absence in burnout and nonburnout groups: a study of Swedish health care workers. Int J Stress Manage 2008;15: 153-172.

17. Huh HJ, Kim SY, Min JA, Chae JH. Development of clinical short-form positive resources test. Stress 2018;26:77-87.

18. Chong PY, Wang WC, Hsieh WC, Lee CY, Chiu NM, Yeh WC, et al. Psychological impact of severe acute respiratory syndrome on health workers in a tertiary hospital. Br J Psychiatry 2004;185:127-133.

19. Maslach C, Jackson SE. The role of sex and family variables in burnout. Sex Roles 1985;12:837-851.

20. Youssef CM, Luthans F. Positive organizational behavior in the workplace: the impact of hope, optimism, and resilience. J Manage 2007; 33:774-800.

21. Sherwin ED, Elliott TR, Rybarczyk BD, Frank RG, Hanson S, Hoffman $J$ et al. Negotiating the reality of caregiving: Hope, burnout and nursing. J Soc Clin Psychol 1992;11:129-139.

22. Son H, Lee WJ, Kim HS, Lee KS, You M. Hospital worker's psychological resilience after the 2015 Middle East respiratory syndrome outbreak. Soc Behav Pers Int J 2019;47:1-13.

23. Glass DC, Mcknight JD. Perceived control, depressive symptomatology, and professional burnout: a review of the evidence. Psychol Health 1996;11:23-48.

24. Brooks SK, Dunn R, Amlôt R, Rubin GJ, Greenberg N. A systematic, thematic review of social and occupational factors associated with psychological outcomes in healthcare employees during an infectious disease outbreak. J Occup Environ Med 2018;60:248-257.

25. Volpone SD, Avery DR. It's self defense: how perceived discrimination promotes employee withdrawal. J Occup Health Psychol 2013;18:430448.

26. Cieslak R, Shoji K, Douglas A, Melville E, Luszczynska A, Benight CC. A meta-analysis of the relationship between job burnout and secondary traumatic stress among workers with indirect exposure to trauma. Psychol Serv 2014;11:75-86.

27. Nirel N, Goldwag R, Feigenberg Z, Abadi D, Halpern P. Stress, work overload, burnout, and satisfaction among paramedics in Israel. Prehosp Disaster Med 2008;23:537-546.

28. Shirom A, Nirel N, Vinokur AD. Overload, autonomy, and burnout as predictors of physicians' quality of care. J Occup Health Psychol 2006; 11:328-342. 